\title{
Análise de fatores e estratificação ambiental na avaliação da adaptabilidade e estabilidade em soja
}

\author{
Osmair Mendonça(1), Valéria Carpentieri-Pípolo(2), Deoclécio Domingos Garbuglio(3) \\ e Nelson da Silva Fonseca Junior ${ }^{(3)}$
}

\begin{abstract}
(1)Tropical Melhoramento e Genética, Rod. Celso Garcia Cid, Km 87, Caixa Postal 387, CEP 86031-610 Cambé, PR. E-mail: osmair@sercomtel.com.br (2)Universidade Estadual de Londrina, Dep. de Agronomia, Rod. Celso Garcia Cid, Km 375, Caixa Postal 6001, CEP 86051-990 Londrina, PR. E-mail: pipolo@uel.br (3)Instituto Agronômico do Paraná, Área de Melhoramento e Genética Vegetal, Rod. Celso Garcia Cid, Km 375, Caixa Postal 481, CEP 86047-902 Londrina, PR. E-mail: deocleciodg@yahoo.com.br, nsfjr@iapar.br
\end{abstract}

\begin{abstract}
Resumo - O objetivo deste trabalho foi avaliar a eficiência de diferentes métodos de estratificação ambiental, a representatividade dos locais de avaliação, e a adaptabilidade e estabilidade de genótipos de soja, por meio de ensaios de produtividade de grãos, nos estados do Paraná e Santa Catarina, nos anos agrícolas de 2000 a 2003 , em um total de 15 ambientes. Foram utilizados, para estratificação ambiental, o método tradicional de Lin e a análise de fatores aliada ao porcentual de parte simples (PS\%) da interação genótipo vs. ambiente (GxA). $\mathrm{Na}$ determinação da adaptabilidade e estabilidade dos genótipos, foram utilizados modelos baseados em regressão linear única e bissegmentada. Foram testados 21 genótipos de soja em delineamento de blocos ao acaso com três repetições, na avaliação da produtividade de grãos. O genótipo RB 605 apresenta ampla faixa de adaptação com elevada produtividade média de grãos. De acordo com ambos os métodos, as localidades de Palotina e Brasilândia do Sul podem ser reduzidas a somente um local de ensaio.A análise de fatores associada ao PS\% da interação GxA é mais seletiva para estratificação ambiental, em relação ao método tradicional de Lin.
\end{abstract}

Termos para indexação: Glycine max, interação genótipo x ambiente, previsibilidade.

\section{Factor analysis and environmental stratification in the assessment of soybean adaptability and stability}

\begin{abstract}
The objective of this work was to assess the efficiency of different methods of environmental stratification, the representation level of the evaluation places, and the adaptability and stability of soybean genotypes, through yield trials in the Paraná and Santa Catarina States, Brazil, in the agricultural years of 2000 to 2003, totaling 15 environments. For environmental stratification, the Lin's traditional method and factor analysis, allied to percentage of the simple portion (SP\%) of genotype vs. environment interaction (GxE), were utilized. Adaptability and stability of the genotypes were determined by linear and bisegmented regression models. Twenty one soybean genotypes were evaluated on randomized complete blocks design, comprising three replications, and the analyzed variable was grain yield. RB 605 genotype is highly adapted and presents high yield. According to both methods, Palotina and Brasilândia do Sul localities can be reduced to one trial location. The factor analysis allied to SP\% of GxE interaction is more selective to environmental stratification in relation to the Lin's traditional method.
\end{abstract}

Index terms: Glycine max, genotype x environment interaction, predictability.

\section{Introdução}

Existem diversos métodos para se avaliar o desempenho genotípico. As diferenças entre eles encontram-se nos parâmetros adotados na avaliação, nos procedimentos biométricos empregados para avaliálo, ou na informação ou detalhamento de sua análise (Cruz et al., 2004).
Mariotti et al. (1976) definiram adaptabilidade como a capacidade de os genótipos responderem vantajosamente à melhoria do ambiente, e estabilidade refere-se à capacidade de os genótipos apresentarem comportamento previsível de acordo com variações ambientais. Este último conceito é definido por Morais (1980) como estabilidade de comportamento e não fenotípica, e é o que interessa ao melhorista, uma vez 
que está associado ao conceito de adaptabilidade, ou seja, a estabilidade de um dado genótipo determina, também, a confiabilidade nos parâmetros estimados de adaptabilidade.

Eberhart \& Russell (1966) propuseram um modelo de regressão linear única para se quantificar os níveis de adaptabilidade e estabilidade de determinado conjunto de genótipos, e consideram como ideal genótipos que apresentam alta produtividade média, coeficiente de regressão linear $\left(\beta_{1 \mathrm{i}}\right)$ igual a 1,0, e desvios da regressão $\left(\hat{\sigma}_{\delta \mathrm{i}}^{2}\right)$ tão pequenos quanto possível.

Outros modelos, fundamentados em metodologias de regressão bissegmentada, vêm sendo amplamente utilizados tanto para soja como para milho (Prado et al., 2001; Carvalho et al., 2002; Hamawaki \& Santos, 2003; Oliveira et al., 2004; Silva \& Duarte, 2006; Garbuglio et al., 2007). Nesses modelos, a técnica consiste na formação de subgrupos de ambientes favoráveis e desfavoráveis, onde os índices ambientais $\left(\mathrm{I}_{\mathrm{j}}\right)$, que os definem, apresentam valores positivos ou negativos, respectivamente (Cruz et al., 2004).

Apesar da importância de estudos de adaptabilidade e estabilidade, o critério de recomendação de genótipos pode basear-se apenas na produtividade média obtida nos ambientes testados. Essa estratégia tem sido utilizada intensamente nos programas de melhoramento de soja no Paraná. Contudo, a indicação generalizada, sem considerar a existência de ambientes favoráveis e desfavoráveis, pode beneficiar ou prejudicar os genótipos com adaptação específica a esses ambientes (Carneiro, 1998).

Devido ao elevado custo financeiro que os ensaios de avaliações finais requerem, é fundamental identificar se há, entre os ambientes disponíveis, padrões similares de respostas de genótipos, por meio de técnicas de estratificação ambiental. Assim torna-se possível uma eventual redução no número de ambientes quando existem problemas técnicos ou escassez de recursos.

As interações de genótipos com ambientes trazem aos melhoristas dificuldades na identificação de genótipos superiores tanto no momento da seleção quanto na recomendação de cultivares (Oliveira et al., 2003; Garbuglio et al., 2007). A presença dessas interações indica que o comportamento relativo dos genótipos nos ambientes de testes depende, fundamentalmente, das condições ambientais a que estão submetidos (Kang, 1998).
Entre os métodos de estratificação ambiental, citamse os que procuram formar subgrupos homogêneos, em que a interação genótipo vs. ambiente (GxA) seja nãosignificativa (Lin, 1982) ou, em outros casos, significativa, mas de natureza predominantemente simples (Cruz \& Castoldi, 1991). O método definido por Cruz \& Castoldi (1991) procura quantificar o porcentual de parte simples atuante (PS\%) da interação GxA, em que as posições relativas dos genótipos de um ambiente para outro não sofram alterações relevantes ou que comprometam as recomendações dos genótipos.

Murakami \& Cruz (2004) propuseram um método que reúne as análises de adaptabilidade e estratificação ambiental, simultaneamente, pelo princípio da similaridade do desempenho genotípico, que se baseia na técnica multivariada de análise de fatores. Esta técnica permite reduzir um grande número de variáveis originais a um pequeno número de variáveis abstratas, também chamadas de fatores. Dessa forma, dentro de cada fator, são reunidas variáveis originais fortemente correlacionadas entre si, mas fracamente correlacionadas com as dos demais fatores.

Os objetivos deste trabalho foram investigar a eficiência de diferentes métodos de estratificação ambiental, conhecer o grau de representatividade dos locais onde são conduzidos os ensaios nos estados do Paraná e Santa Catarina, e avaliar a adaptabilidade e estabilidade de genótipos de soja.

\section{Material e Métodos}

Nos anos agrícolas 2000/2001, 2001/2002 e 2002/2003 foram avaliados 17 genótipos do grupo de maturação semiprecoce, pertencentes ao programa de melhoramento da Milenia - Biotecnologia e Genética. Foram utilizados como testemunhas os genótipos BR 48 e BRS 133 procedentes da Embrapa Soja, e os genótipos CD 201 e CD 202, da Cooperativa Central de Pesquisa Agrícola (Coodetec), perfazendo um total de 21 tratamentos.

As análises foram realizadas utilizando-se dados referentes à variável produtividade de grãos, corrigidos para 13\% de umidade. Esses dados foram obtidos em ensaios conduzidos em Brasilândia do Sul (23⒌ $51^{\prime} \mathrm{S}$ e altitude de $400 \mathrm{~m}$ ), Cascavel (24\%57'S e altitude de $750 \mathrm{~m}$ ), Castro (244' S e altitude de $990 \mathrm{~m}$ ), Centenário do Sul ( $22^{\circ} 50^{\prime} \mathrm{S}$ e altitude de $\left.350 \mathrm{~m}\right)$, Entre Rios $\left(25^{\circ} 55^{\prime} \mathrm{S}\right.$ e altitude de $1.095 \mathrm{~m})$, Faxinal $\left(24^{\circ} 0^{\prime} \mathrm{S}\right.$ e altitude de $\left.700 \mathrm{~m}\right)$, Guarapuava $\left(25^{\circ} 21^{\prime} \mathrm{S}\right.$ e altitude de $\left.1.058 \mathrm{~m}\right)$, Marilândia 
do Sul (2350'S e altitude de $850 \mathrm{~m})$, Palotina ( $24^{\circ} 18^{\prime} \mathrm{S}$ e altitude de $310 \mathrm{~m}$ ), no Estado do Paraná, e Abelardo Luz (2555'S e altitude de 930 m), em Santa Catarina.

O delineamento experimental utilizado foi o de blocos ao acaso, com três repetições. Cada parcela foi constituída de quatro linhas de $5 \mathrm{~m}$, com espaçamento de $0,45 \mathrm{~m}$. As duas linhas externas de cada parcela, e $0,50 \mathrm{~m}$, em cada extremidade das duas linhas centrais, foram descartadas como bordadura. A densidade de plantas estabelecidas nos ensaios variou de 27 a 35 plantas por metro quadrado, prevalecendo populações maiores nos ensaios dos locais norte e noroeste do Estado do Paraná (Palotina, Brasilândia do Sul e Centenário do $\mathrm{Sul})$.

As análises de variância foram realizadas em cada local e ano e, após verificada a homogeneidade das variâncias residuais, realizou-se a análise conjunta. As análises de estratificação ambiental foram realizadas pelo método tradicional proposto por Lin (1982), e pela análise de fatores proposta por Murakami \& Cruz (2004). Foi estimada também a fração simples (PS\%) da interação GxA, de acordo com o método de Cruz \& Castoldi (1991).

Segundo Cruz \& Carneiro (2003), o número de fatores finais considerados na estratificação ambiental, pela análise de fatores, pode ser igual ao número de autovalores iguais ou superiores a 1,0. Porém, podem ocorrer situações em que a proporção da variação explicada pelos autovalores maiores que 1,0 seja relativamente baixa. Assim, é necessário que se considere mais fatores até que se atinja, pelo menos, $80 \%$ da variabilidade total. Neste trabalho, consideraramse seis fatores finais para o agrupamento, uma vez que os seis primeiros autovalores absorveram $83,5 \%$ da variação total.

$\mathrm{O}$ agrupamento dos ambientes foi considerado a partir de cargas fatoriais finais, calculadas após rotação, maiores que 0,70 , por indicarem que esses ambientes apresentam alta correlação e podem ser agrupados em um mesmo fator (Cruz \& Carneiro, 2003). Cargas fatoriais de valores iguais ou abaixo de 0,50 indicam que o ambiente em questão não deve pertencer ao grupo. Para cargas fatoriais com valores entre 0,50 e 0,70 , não há garantia de definição para o agrupamento (Murakami \& Cruz, 2004).

O comportamento da produtividade de grãos dos genótipos, em relação aos parâmetros de adaptabilidade e estabilidade, foi avaliado por meio das metodologias de regressão linear única (Eberhart \& Russel, 1966) e regressão bissegmentada (Cruz et al., 1989).
O modelo adotado nas análises de regressão bissegmentada (Cruz et al.,1989) foi:

$Y_{i j}=\beta_{0 i}+\beta_{l i} I_{j}+\beta_{2 i} T\left(I_{j}\right)+\sigma_{i j}+e_{i j}$, em que: $Y_{i j}$ é a média do genótipo i no ambiente $\mathrm{j} ; \mathrm{I}_{\mathrm{j}}$ é o índice ambiental; $\mathrm{T}\left(\mathrm{I}_{\mathrm{j}}\right)=0$ se $\mathrm{I}_{\mathrm{j}}<0 ; \mathrm{T}\left(\mathrm{I}_{\mathrm{j}}\right)=\mathrm{I}_{\mathrm{j}}-\mathrm{I}_{+}$se $\mathrm{I}_{\mathrm{j}}>0$, em que $\mathrm{I}_{+}$é a média dos índices $\mathrm{I}_{\mathrm{j}}$ positivos; $\beta_{0 \mathrm{i}}$ é a média geral da genótipo i; $\beta_{1 \mathrm{i}}$ é o coeficiente de regressão linear associado a $\mathrm{I}_{\mathrm{j}} ; \beta_{2 \mathrm{i}}$ é o coeficiente de regressão linear associado a $\mathrm{T}\left(\mathrm{I}_{\mathrm{j}}\right) ; \sigma_{\mathrm{ij}}$ é o desvio da regressão linear; $\mathrm{e}_{\mathrm{ij}}$ é o erro médio experimental. O modelo utilizado na análise de regressão linear única (Eberhart \& Russel, 1966) se diferencia do modelo de regressão bissegmentada por não apresentar o componente $\beta_{2 \mathrm{i}} \mathrm{T}\left(\mathrm{I}_{\mathrm{j}}\right)$ no modelo. Os demais componentes apresentam a mesma definição do modelo de regressão bissegmentada. As análises foram realizadas com auxílio dos programas Genes (Cruz, 2005) e SAS (SAS Institute, 1999).

\section{Resultados e Discussão}

Nas análises de variância individuais, com exceção dos experimentos de Faxinal (ambiente 10) e Cascavel (ambiente 6), os genótipos apresentaram comportamento distinto $(\mathrm{p}<0,01)$ dentro de cada ambiente (Tabela 1$)$. Os coeficientes de variação (CV) oscilaram entre $8,74 \%$ (ambiente 15) e 20,19 (ambiente 12), com média de $13,73 \%$, semelhantes aos obtidos no Paraná, por Carvalho et al. (2002), em que os CVs variaram de 9,15 a 13,53\%, e aos obtidos por Di Mauro et al. (2000), em São Paulo, que obtiveram média de $11,20 \%$. As médias de produtividade de grãos dos ensaios ficaram compreendidas entre $2.678 \mathrm{~kg} \mathrm{ha}^{-1}$ (ambiente 4) e $5.833 \mathrm{~kg} \mathrm{ha}^{-1}$ (ambiente 6), com média geral de $3.585 \mathrm{~kg} \mathrm{ha}^{-1}$.

A razão entre o maior e o menor valor para os quadrados médios do erro foi de 6,68. Banzato \& Kronka (1992) mencionam que uma razão menor que sete indica que há homogeneidade das variâncias residuais obtidas nas análises, o que possibilita a realização da análise conjunta sem qualquer restrição dos locais.

A partir da análise conjunta, constatou-se que as fontes de variação genótipos, ambientes e interação GxA foram significativas. A interação GxA significativa indica que os genótipos avaliados apresentaram comportamento diferenciado em cada ambiente e que há mudança na magnitude das respostas para o caráter produtividade de grãos devido à variação ambiental, o que justifica a realização da estratificação ambiental. 
Com base em valores relativos aos parâmetros de adaptabilidade e de estabilidade, segundo o modelo de Eberhart \& Russel (1966) (Tabela 2), pode-se verificar que I910-1P e RB 501 apresentaram coeficiente de regressão $\left(\beta_{1 \mathrm{i}}\right)$ significativo e superior a $1,0 \mathrm{e}$ coeficientes de determinação $\left(\mathrm{R}^{2}\right)$ acima de $80 \%$. Esses resultados sugerem que esses genótipos possuem grande capacidade de explorar vantajosamente os estímulos ambientais favoráveis com certa estabilidade, embora tenham apresentado variância dos desvios de regressão

Tabela 1. Ambientes e anos de avaliação, qualidade de acordo com os índices ambientais (Ij), quadrados médios dos tratamentos e do erro das análises de variância individuais, produtividade média dos ensaios e coeficientes de variação ambiental $\left(\mathrm{CV}_{\mathrm{e}}\right)$.

\begin{tabular}{|c|c|c|c|c|c|c|}
\hline \multirow[t]{2}{*}{ Ambiente } & \multirow[t]{2}{*}{ Ano } & \multirow[t]{2}{*}{$\mathrm{I}_{\mathrm{j}}^{(1)}$} & \multicolumn{2}{|c|}{ Quadrados médios } & \multirow{2}{*}{$\begin{array}{l}\text { Produtividade } \\
\left(\mathrm{kg} \mathrm{ha}^{-1}\right)\end{array}$} & \multirow{2}{*}{$\begin{array}{l}\mathrm{CV}_{\mathrm{e}} \\
(\%)\end{array}$} \\
\hline & & & Tratamentos $\left(\times 10^{5}\right)$ & Erro $\left(\times 10^{4}\right)$ & & \\
\hline 1.Palotina & $2002 / 2003$ & $\mathrm{I}_{+}$ & 22,44 & $39,70 * *$ & 3.745 & 16,83 \\
\hline 2.Brasilândia do Sul & $2002 / 2003$ & $\mathrm{I}-$ & 3,45 & $11,26 * *$ & 3.335 & 10,06 \\
\hline 3.Marilândia do Sul & $2002 / 2003$ & $\mathrm{I}-$ & 4,96 & $20,73 * *$ & 3.133 & 14,53 \\
\hline 4.Entre Rios & $2002 / 2003$ & I- & 3,73 & $14,19 * *$ & 2.678 & 14,06 \\
\hline 5.Abelardo Luz & $2002 / 2003$ & $\mathrm{I}_{+}$ & 8,30 & $43,60 *$ & 4.154 & 15,89 \\
\hline 6.Cascavel & $2002 / 2003$ & $\mathrm{I}_{+}$ & 8,18 & 52,82 & 5.833 & 12,46 \\
\hline 7.Castro & $2002 / 2003$ & $\mathrm{I}-$ & 3,86 & $18,89^{*}$ & 3.034 & 14,33 \\
\hline 8.Centenário do Sul & $2002 / 2003$ & $\mathrm{I}_{+}$ & 4,87 & $22,91 *$ & 4.085 & 11,72 \\
\hline 9.Faxinal & $2002 / 2003$ & $\mathrm{I}-$ & 3,10 & 17,55 & 3.351 & 12,50 \\
\hline 10.Marilândia do Sul & $2001 / 2002$ & $\mathrm{I}-$ & 4,83 & $12,08 * *$ & 3.551 & 9,79 \\
\hline 11.Castro & $2001 / 2002$ & $\mathrm{I}-$ & 4,69 & $18,35^{* *}$ & 3.535 & 12,12 \\
\hline 12.Guarapuava & $2001 / 2002$ & $\mathrm{I}-$ & 13,40 & $35,63 * *$ & 2.956 & 20,19 \\
\hline 13.Palotina & $2000 / 2001$ & $\mathrm{I}_{+}$ & 6,03 & $32,75^{*}$ & 4.178 & 13,70 \\
\hline 14.Guarapuava & $2000 / 2001$ & I- & 10,51 & $32,31 * *$ & 2.990 & 19,01 \\
\hline 15.Brasilândia do Sul & $2000 / 2001$ & $\mathrm{I}-$ & 4,50 & $7,91 * *$ & 3.218 & 8,74 \\
\hline Média & & & & & 3.585 & 13,73 \\
\hline
\end{tabular}

${ }^{(1)} \mathrm{I}_{+}$: ambiente favorável; I-: ambiente desfavorável, definidos pelos índices ambientais. * e **Significativo a 5 e $1 \%$ de probabilidade, respectivamente, pelo teste F.

Tabela 2. Produtividade média em kg ha ${ }^{-1}\left(\beta_{0}\right)$, estimativas dos coeficientes de regressão $\left(\beta_{1 i}, \beta_{1}, \beta_{1+} \beta_{2}\right)$, variância dos desvios de regressão $\left(\hat{\sigma}_{\delta \mathrm{i}}^{2}\right)$ e coeficiente de determinação $\left(\mathrm{R}^{2}\right)$, dos 21 genótipos de soja estudados, pelos métodos de Eberhart \& Russel (1966) e Cruz et al. (1989).

\begin{tabular}{|c|c|c|c|c|c|c|c|c|c|c|}
\hline \multirow[t]{2}{*}{ Genótipo } & \multicolumn{4}{|c|}{ Eberhart \& Russel } & \multicolumn{6}{|c|}{ Cruz et al. ${ }^{(1)}$} \\
\hline & $\beta_{0}$ & $\beta_{1 \mathrm{i}}$ & $\hat{\sigma}_{\delta \mathrm{i}}^{2}\left(\mathrm{x} 10^{3}\right)$ & $\mathrm{R}^{2}$ & $\mathrm{I}$ & $\mathrm{I}_{+}$ & $\beta_{1}$ & $\beta_{1+} \beta_{2}$ & $\hat{\sigma}_{\delta \mathrm{i}}^{2}\left(\mathrm{x} 10^{3}\right)$ & $\mathrm{R}^{2}$ \\
\hline BR 48 & 3.971 & 0,98 & 39,14 & 83 & 3.484 & 4.947 & 1,10 & 0,72 & 27,66 & 86 \\
\hline BRS 133 & 3.820 & 1,12 & $252,74 * *$ & 70 & 3.267 & 4.926 & $1,37 *$ & $0,59 * *$ & $188,23 * *$ & 78 \\
\hline CD 201 & 3.753 & 1,01 & $85,08^{*}$ & 79 & 3.382 & 4.495 & 0,85 & 1,33 & 64,82 & 83 \\
\hline CD 202 & 3.763 & 1,05 & $122,08 * *$ & 77 & 3.398 & 4.492 & 0,81 & $1,56^{*}$ & 53,66 & 86 \\
\hline I $815-12 \mathrm{P}$ & 3.325 & 1,02 & $316,47 * *$ & 62 & 2.772 & 4.430 & $1,41^{*}$ & $0,21^{*}$ & $131,22 * *$ & 81 \\
\hline I $815-4 \mathrm{P}$ & 3.312 & 0,81 & 26,61 & 79 & 2.968 & 4.000 & 0,86 & 0,71 & 32,08 & 80 \\
\hline I $816-4(\mathrm{M})$ & 3.569 & 0,93 & $94,28^{*}$ & 76 & 3.140 & 4.428 & 1,04 & 0,70 & $90,79 *$ & 78 \\
\hline I $816-4(\mathrm{PI})$ & 3.865 & 1,02 & 56,67 & 83 & 3.403 & 4.790 & 1,10 & 0,86 & 59,24 & 84 \\
\hline I $816-7 \mathrm{P}$ & 3.600 & $0,77 * *$ & 12,92 & 84 & 3.280 & 4.241 & 0,83 & 0,66 & 11,27 & 85 \\
\hline I $834-2$ & 3.759 & 0,95 & $78,30 *$ & 78 & 3.351 & 4.577 & 0,98 & 0,88 & $90,31 *$ & 78 \\
\hline I $849-1 P$ & 3.719 & 0,91 & $68,64^{*}$ & 78 & 3.326 & 4.505 & 0,95 & 0,84 & $79,49^{*}$ & 78 \\
\hline I $864-8$ & 3.680 & $0,79 * *$ & 35,84 & 77 & 3.400 & 4.239 & $0,72 *$ & 0,95 & 37,54 & 78 \\
\hline I $907-4 \mathrm{P}$ & 3.251 & 1,10 & $75,22 *$ & 83 & 2.841 & 4.069 & 1,05 & 1,21 & $84,47 *$ & 83 \\
\hline I $910-1 \mathrm{P}$ & 3.420 & $1,20 * *$ & $81,57^{*}$ & 85 & 2.964 & 4.334 & 1,11 & $1,39 * *$ & $83,37^{*}$ & 86 \\
\hline I $913-2 \mathrm{P}$ & 3.446 & 1,00 & $120,36^{* *}$ & 76 & 3.080 & 4.178 & 0,96 & 1,10 & $134,63 * *$ & 76 \\
\hline I $920-3$ & 3.305 & 1,01 & $104,03 * *$ & 78 & 2.912 & 4.091 & 0,99 & 1,05 & $119,25^{* *}$ & 78 \\
\hline I $921-2(\mathrm{PI}) \mathrm{P}$ & 3.509 & 1,09 & 48,76 & 85 & 3.043 & 4.441 & 1,18 & 0,91 & 48,57 & 86 \\
\hline I $935-1 \mathrm{P}$ & 3.230 & 0,94 & $175,73 * *$ & 68 & 2.980 & 3.729 & $0,66^{*}$ & $1,53^{*}$ & $82,41 * *$ & 81 \\
\hline I $944-2 P$ & 3.656 & 0,92 & $213,48^{* *}$ & 65 & 3.257 & 4.453 & 1,02 & 0,71 & $224,17^{* *}$ & 66 \\
\hline RB 501 & 3.508 & $1,39 *$ & $63,98^{*}$ & 89 & 2.944 & 4.636 & $1,33^{*}$ & $1,51^{*}$ & $71,77^{*}$ & 90 \\
\hline RB 605 & 3.828 & 0,97 & $276,88^{*}$ & 62 & 3.552 & 4.380 & $0,67 *$ & $1,60 *$ & $176,00 * *$ & 75 \\
\hline Média & 3.585 & & & & 3.178 & 4.399 & & & & \\
\hline
\end{tabular}

(1)Média nos ambientes desfavoráveis (I-) e favoráveis $\left(\mathrm{I}_{+}\right)$, em $\mathrm{kg} \mathrm{ha}^{-1}$. * e **Significativo a 5 e $1 \%$ de probabilidade, respectivamente, pelo teste $t$, nos coeficientes de regressão, e pelo teste $F$, na $\hat{\sigma}_{\delta i}^{2}$. 
$\left(\hat{\sigma}_{\delta \mathrm{i}}^{2}\right)$ significativa pelo teste $\mathrm{F}(\mathrm{p}<0,05)$, e produtividades abaixo da média geral $\left(3.585 \mathrm{~kg} \mathrm{ha}^{-1}\right)$.

Os genótipos I816-7P e I864-8, mesmo com $\beta_{1 \mathrm{i}}$ abaixo de 1,0 e significativos, obtiveram $\hat{\sigma}_{\delta i}^{2}$ nãosignificativas e coeficientes de determinação elevados (84 e 77\%, respectivamente), e mostraram-se estáveis e previsíveis, além de produtivos, com rendimentos superiores à média geral (3.600 e $3.680 \mathrm{~kg} \mathrm{ha}^{-1}$, respectivamente).

Os demais genótipos apresentaram $\beta_{1 \mathrm{i}}$ nãosignificativos $\left(\beta_{1 \mathrm{i}}=1\right)$ pelo teste $\mathrm{t}(\mathrm{p}>0,05)$, o que indica desempenho diretamente proporcional à melhoria do ambiente. Os genótipos BR 48, BRS 133, CD 201, CD 202, I816-4(PI), I849-1P, I944-2P e RB 605 apresentaram produtividades superiores à média geral (3.585 $\left.\mathrm{kg} \mathrm{ha}^{-1}\right)$ e possuem, portanto, elevada adaptabilidade ao conjunto de ambientes.

Os genótipos BRS 133, CD 201, CD 202, I815-12P, I816-4(M), I834-2, I849-1P, I907-4P, I910-1P, I913-2P, I920-3, I935-1P, I944-2P, RB 501 e RB 605 apresentaram desvios de regressão significativos (Tabela 2), no entanto, apenas os genótipos I815-12P, I935-1P, I944-2P e RB 605 alcançaram valores de $\mathrm{R}^{2}$ abaixo de $70 \%$, o que sugere instabilidade quanto às variações ambientais (Cruz et al., 2004).

Ao se considerar o parâmetro produtividade média $\left(\beta_{\mathrm{o}}\right)$ no modelo de Cruz et al. (1989), verifica-se que o genótipo I864-8 mostrou-se pouco responsivo à ambientes I- $\left(\beta_{1}<1\right)$, além de apresentar $\hat{\sigma}_{\delta \mathrm{i}}^{2}$ nãosignificativa e $\mathrm{R}^{2}$ acima de $75 \%$, com alta estabilidade e adaptabilidade média à ambientes $I_{+}\left(\beta_{1}+\beta_{2}=1\right)$, além de produtividades acima da média geral e da média nos ambientes I-.

Embora o genótipo RB 605 tenha apresentado $\hat{\sigma}_{\delta \mathrm{i}}^{2}$ maior que zero, obteve alta produtividade em ambientes $\mathrm{I}_{+}$, I-, na média geral, além de um $\mathrm{R}^{2}$ acima de $75 \%$. Segundo Garbuglio et al. (2007), a $\hat{\sigma}_{\delta \mathrm{i}}^{2}$ não deve ser o único fator a se levar em consideração em uma provável recomendação de genótipos, com foco na estabilidade, principalmente se este genótipo apresenta instabilidade dentro de uma faixa de elevada produtividade. Pode-se citar o caso do genótipo BRS 133 que, apesar de ter apresentado $\hat{\sigma}_{\delta \mathrm{i}}^{2}$ significativa, alta responsividade a ambientes I- e baixa responsividade a ambientes $\mathrm{I}_{+}$, foi o que alcançou a terceira maior média de produtividade (3.820 kg ha-1), a segunda maior média (4.926 kg ha-1) em ambientes $\mathrm{I}_{+}$, e produtividade de $3.267 \mathrm{~kg} \mathrm{ha}^{-1} \mathrm{em}$ ambientes I-, acima da média desses ambientes $\left(3.178 \mathrm{~kg} \mathrm{ha}^{-1}\right)$.
Os genótipos CD 202, I935-1P, RB 501 e RB 605 apresentaram alta responsividade a ambientes $\mathrm{I}_{+}$ $\left(\beta_{1}+\beta_{2}>1\right)$ com médias gerais compreendidas entre $3.230 \mathrm{~kg} \mathrm{ha}^{-1}$ e $3.828 \mathrm{~kg} \mathrm{ha}^{-1}$. Entre esses quatro genótipos, apenas CD 202 apresentou $\hat{\sigma}_{\delta \mathrm{i}}^{2}$ nãosignificativa e $\mathrm{R}^{2}$ de $86 \%$. Os genótipos I935-1P e RB 605 apresentaram baixa responsividade a ambientes I- $\left(\beta_{1}<1\right)$. RB 501 apresentou alta responsividade a ambientes I-, $\mathrm{R}^{2}$ de $90 \%$, o que indica uma estabilidade considerável, porém, sua produtividade média $\left(3.508 \mathrm{~kg} \mathrm{ha}^{-1}\right)$ foi inferior à média geral e a produtividade em ambientes I- $\left(2.944 \mathrm{~kg} \mathrm{ha}^{-1}\right)$ foi inferior à média nesses ambientes $\left(3.178 \mathrm{~kg} \mathrm{ha}^{-1}\right)$. Ou seja, com base somente nos parâmetros do modelo, essa cultivar poderia ser indicada para ambientes I-, no entanto, pelas médias de produtividade, verifica-se que outros genótipos seriam mais indicados nesse tipo de ambiente, principalmente quando se leva em consideração que a maioria das áreas produtoras de soja, assim como de outras culturas, são classificadas como ambientes desfavoráveis em virtude do baixo controle ambiental que se atinge, em comparação aos experimentos de campo. Isto pode ser constatado pela média de produtividade nacional de $2.863 \mathrm{~kg} \mathrm{ha}^{-1}$, com variação de $2.630 \mathrm{~kg} \mathrm{ha}^{-1}$, na Região Norte, a $2.910 \mathrm{~kg} \mathrm{ha}^{-1}$, na Região Centro-Oeste (Conab, 2007).

Os genótipos I816-4(M), I834-2, I849-1P, I907-4P, I913-2P, I920-3 e I944-2P apresentaram baixa estabilidade $\left(\hat{\sigma}_{\delta \mathrm{i}}^{2}>0\right)$ e, com exceção do I944-2P, apresentaram $\mathrm{R}^{2}$ acima de $70 \%$. Os demais genótipos apresentaram, em geral, responsividades médias tanto em ambientes $\mathrm{I}_{+}$quanto I-, com $\hat{\sigma}_{\delta \mathrm{i}}^{2}$ não-significativas, o que torna possível considerá-los como de ampla adaptação, devendo-se levar em consideração, no entanto, suas produtividades. Os coeficientes de determinação $\mathrm{R}^{2}$ foram considerados satisfatórios, o que indica que as retas de regressão estabelecidas para cada genótipo explicaram bem seus comportamentos frente às variações ambientais.

Pelo método de Cruz et al. (1989), o genótipo que melhor atendeu à proposta do modelo foi RB 605, com produtividade de grãos $\left(3.828 \mathrm{~kg} \mathrm{ha}^{-1}\right)$ superior à média do ensaio, alta adaptação a ambientes $\mathrm{I}_{+} \mathrm{e}$ baixa resposta a ambientes I-. No entanto, apresentou $\hat{\sigma}_{\delta \mathrm{i}}^{2}$ significativa e, ainda com base nesses parâmetros, a genótipo I815-12P foi o menos adaptado, com $\beta_{1}+\beta_{2}<1, \beta_{\mathrm{i}}>1$, e mostrou-se instável, com $\hat{\sigma}_{\delta \mathrm{i}}^{2}>0$.

O genótipo I944-2P, tanto no modelo de regressão linear única quanto bissegmentada, apresentou valores 
de $\mathrm{R}^{2}$ abaixo de $70 \%, \hat{\sigma}_{\delta \mathrm{i}}^{2}$ altamente significativa e coeficiente de regressão não-significativo em ambos os métodos. No entanto, apresentou produtividades superiores à geral, em ambientes $\mathrm{I}_{+} \mathrm{e} \mathrm{I}-$, o que o torna um genótipo de elevado potencial produtivo, porém, com adaptabilidade média. Outros genótipos que apresentaram magnitudes semelhantes nos parâmetros testados foram I815-12P, I935-1P e RB 605. Com exceção do último, os demais apresentaram média inferior à geral e à de ambientes I-.

Mesmo materiais que apresentam parâmetros contrários ao recomendado pelo modelo de regressão bissegmentada devem ter suas médias analisadas mais cuidadosamente. Como exemplo, pode-se citar o caso do genótipo BRS 133 que apresentou alta responsividade em ambientes I-, baixa resposta a ambientes $\mathrm{I}_{+}$e $\hat{\sigma}_{\delta \mathrm{i}}^{2}$ significativa. Somente pelos parâmetros, o genótipo poderia ser considerado instável e de baixa adaptação, no entanto alcançou a terceira maior média de produtividade dos ensaios ( $\left.3.820 \mathrm{~kg} \mathrm{ha}^{-1}\right)$, a segunda média em ambientes $\mathrm{I}_{+}$e produtividade acima da média geral em ambientes I-. Garbuglio et al. (2007) atribuem esse fenômeno a uma possível falha no modelo, uma vez que o fato de um genótipo ser pouco responsivo em ambiente I- previne que a reta da equação de regressão não atinja pontos inferiores em ambientes mais pobres. No entanto, se ela apresentar inclinação de $\beta_{1} \geq 1$, e se a média estiver entre as mais elevadas, o genótipo será promissor e, nesse caso, a metodologia pouco contribui para o entendimento de falta de resposta à melhoria dos ambientes favoráveis.

No caso dos genótipos BR 48 e I816-4(PI), que apresentaram as maiores médias de produtividade (3.971 e $3.865 \mathrm{~kg} \mathrm{ha}^{-1}$, respectivamente), os parâmetros $\beta_{1}$ e $\beta_{1}+\beta_{2}$, obtidos por regressão bissegmentada, bem como $\beta_{1 \mathrm{i}}, \hat{\sigma}_{\delta \mathrm{i}}^{2}$ pelo modelo de regressão linear única, foram não-significativos, o que se constitui numa evidência de responsividade média no conjunto de ambientes. Porém, os valores de $\mathrm{R}^{2}$ acima de $80 \%$ nos dois modelos, e a não-significância das estimativas das $\hat{\sigma}_{\delta \mathrm{i}}^{2}$, indicam que os materiais mostram-se estáveis diante de variações ambientais, com elevado potencial produtivo. Os genótipos I815-4P e I921-2(PI)P apresentaram parâmetros similares, porém suas produtividades médias ficaram 16,6 e 11,6\% abaixo de BR 48 e, também, da média geral.

Pelo método tradicional, baseado no algoritmo de Lin (1982), os ambientes foram distribuídos em seis grupos (Tabela 3). Os ambientes 1, 6 e 11, em razão da alta influência da porção complexa da interação GxA, não foram alocados em nenhum dos grupos formados e nem puderam originar novos grupos.

De acordo com o método de Cruz \& Castoldi (1991), das 105 combinações possíveis entre os 15 ambientes em estudo (Tabela 4), apenas três ( $1 \times 2,4 \times 10$ e $12 \times 14)$ apresentaram interação GxA com predominância de parte simples (PS\%>50) e correlações acima de 0,50.

$\mathrm{Na}$ técnica de análise de fatores (Tabela 5), proposta por Murakami \& Cruz (2004), as comunalidades, com excessão no ambiente 3 , apresentaram valores acima de 0,64 , o que evidencia alta eficiência na representação das variáveis por uma parte comum. Segundo Cruz \& Carneiro (2003), valores de comunalidades superiores a 0,64 têm sido aceitos como razoáveis, pois são equivalentes a uma correlação próxima de 0,80 entre a variável padronizada e a parte comum, que explica esta variável.

O fator 1 permitiu o agrupamento dos ambientes 4, 9 e 10, que tiveram cargas fatoriais acima de 0,70. $\mathrm{O}$ fator 2 agrupou, com o ambiente 13 e 14, pertencentes a safra 2000/2001, o ambiente 12 (safra 2001/2002), também com cargas fatoriais acima de 0,80 . Neste caso, foram agrupados três ambientes, sendo dois deles uma mesma localidade, porém em safras distintas (Guarapuava 2000/2001 e 2001/2002), com uma correlação entre ambientes de 0,98 e $88,2 \%$ de PS, podendo-se inferir que as diferenças que ocorreram entre as safras, nessas localidades, não afetaram o ranqueamento dos genótipos.

Os fatores 3 e 4 agruparam somente um ambiente cada, 6 e 11, respectivamente. A presença de apenas um ambiente no fator 3 pode ter como explicação a alta produtividade de grãos alcançada naquela localidade (5.833 $\left.\mathrm{kg} \mathrm{ha}^{-1}\right)$. Quanto ao fator 4, não se detectou uma razão particular para o agrupamento. Os ambientes $7 \mathrm{e}$ 8 foram agrupados no fator 5 , possivelmente em razão da ausência de interação GxA detectada pelo método de Lin (Tabela 5), que também os alocou em um mesmo grupo (Tabela 3). Os ambientes 3, 5 e 15 não puderam

Tabela 3. Agrupamento dos 15 ambientes, segundo o método proposto por Lin (1982).

\begin{tabular}{llccc}
\hline Grupo & \multicolumn{1}{c}{ Ambiente $^{(1)}$} & $\begin{array}{c}\text { Quadrados médios dos } \\
\text { erros }\left(\times 10^{3}\right)\end{array}$ & Calculado & Tabelado (5\%) \\
\hline A & 12, 14 e 3 & 95,47 & 1,13 & 1,41 \\
B & 4, 10, 9, 2, 3, 7, 8 e 13 & 99,27 & 1,17 & 1,23 \\
C & 4 e 5 & 100,63 & 1,19 & 1,58 \\
D & 13 e 15 & 11,27 & 1,32 & 1,58 \\
E & 5 e 9 & 127,61 & 1,51 & 1,58 \\
F & 5 e 10 & 129,45 & 1,53 & 1,58 \\
\hline
\end{tabular}

(1) Ambientes descritos na Tabela 1. 
ser associados a quaisquer dos seis fatores, uma vez que suas cargas fatoriais ficaram abaixo de 0,70 .
Palotina e Brasilândia do Sul, pelo método de Lin, foram agrupadas somente na safra 2000/2001 (grupo D),

Tabela 4. Porcentagem de parte simples (PS\%) da interação genótipo x ambiente e estimativas de correlações entre ambientes (r), nas 105 combinações possíveis entre os ambientes estudados.

\begin{tabular}{|c|c|c|c|c|c|c|c|c|}
\hline Ambiente $^{(1)}$ & $\mathrm{r}$ & $\mathrm{PS} \%$ & Ambiente & $\mathrm{r}$ & PS $\%$ & Ambiente & $\mathrm{r}$ & $\mathrm{PS} \%$ \\
\hline $1 \times 2$ & 0,64 & 74,4 & $3 \times 12$ & 0,54 & 46,4 & $7 \times 9$ & 0,29 & 16,3 \\
\hline $1 \times 3$ & 0,11 & 29,5 & $3 \times 13$ & 0,22 & 12,3 & $7 \times 10$ & 0,22 & 12,3 \\
\hline $1 \times 4$ & 0,17 & 40,1 & $3 \times 14$ & 0,60 & 46,2 & $7 \times 11$ & $-0,29$ & $-13,1$ \\
\hline $1 \times 5$ & 0,08 & 15,9 & $3 \times 15$ & $-0,04$ & $-1,9$ & $7 \times 12$ & $-0,16$ & 8,0 \\
\hline $1 \times 6$ & $-0,08$ & 7,3 & $4 \times 5$ & 0,54 & 42,2 & $7 \times 13$ & 0,29 & 18,5 \\
\hline $1 \times 7$ & 0,36 & 51,1 & $4 \times 6$ & 0,31 & 25,2 & $7 \times 14$ & $-0,17$ & 2,3 \\
\hline $1 \times 8$ & 0,43 & 51,1 & $4 \times 7$ & 0,30 & 16,4 & $7 \times 15$ & $-0,29$ & $-13,5$ \\
\hline $1 \times 9$ & 0,46 & 62,9 & $4 \times 8$ & 0,19 & 11,0 & $8 \times 9$ & 0,27 & 17,3 \\
\hline $1 \times 10$ & 0,35 & 45,6 & $4 \times 9$ & 0,64 & 41,0 & $8 \times 10$ & 0,09 & 4,5 \\
\hline $1 \times 11$ & $-0,30$ & 8,7 & $4 \times 10$ & 0,82 & 59,3 & $8 \times 11$ & $-0,17$ & $-8,2$ \\
\hline $1 \times 12$ & $-0,16$ & $-4,7$ & $4 \times 11$ & 0,03 & 2,4 & $8 \times 12$ & $-0,27$ & $-2,4$ \\
\hline $1 \times 13$ & 0,20 & 29,9 & $4 \times 12$ & 0,31 & 36,5 & $8 \times 13$ & 0,05 & 3,0 \\
\hline $1 \times 14$ & $-0,12$ & 0,5 & $4 \times 13$ & 0,08 & 6,8 & $8 \times 14$ & $-0,25$ & $-5,3$ \\
\hline $1 \times 15$ & $-0,32$ & 8,9 & $4 \times 14$ & 0,27 & 28,2 & $8 \times 15$ & $-0,16$ & $-7,6$ \\
\hline $2 \times 3$ & 0,33 & 20,1 & $4 \times 15$ & $-0,35$ & $-16,0$ & $9 \times 10$ & 0,69 & 48,6 \\
\hline $2 \times 4$ & 0,37 & 20,7 & $5 \times 6$ & 0,36 & 20,2 & $9 \times 11$ & $-0,15$ & $-5,2$ \\
\hline $2 \times 5$ & 0,12 & 15,4 & $5 \times 7$ & $-0,21$ & $-3,8$ & $9 \times 12$ & 0,24 & 36,0 \\
\hline $2 \times 6$ & 0,07 & 12,3 & $5 \times 8$ & $-0,26$ & $-9,3$ & $9 \times 13$ & 0,22 & 17,7 \\
\hline $2 \times 7$ & 0,19 & 10,4 & $5 \times 9$ & 0,37 & 33,6 & $9 \times 14$ & 0,24 & 30,6 \\
\hline $2 \times 8$ & 0,42 & 25,8 & $5 \times 10$ & 0,42 & 28,6 & $9 \times 15$ & $-0,54$ & $-22,8$ \\
\hline $2 \times 9$ & 0,51 & 30,4 & $5 \times 11$ & 0,02 & 5,0 & $10 \times 11$ & $-0,19$ & $-9,0$ \\
\hline $2 \times 10$ & 0,51 & 32,1 & $5 \times 12$ & 0,21 & 14,1 & $10 \times 12$ & 0,29 & 28,7 \\
\hline $2 \times 11$ & $-0,30$ & $-13,1$ & $5 \times 13$ & 0,07 & 5,0 & $10 \times 13$ & 0,22 & 12,5 \\
\hline $2 \times 12$ & 0,01 & 19,9 & $5 \times 14$ & 0,23 & 13,3 & $10 \times 14$ & 0,28 & 23,2 \\
\hline $2 \times 13$ & 0,24 & 17,0 & $5 \times 15$ & $-0,05$ & 2,1 & $10 \times 15$ & $-0,33$ & $-15,3$ \\
\hline $2 \times 14$ & 0,02 & 14,9 & $6 \times 7$ & $-0,23$ & $-4,8$ & $11 \times 12$ & 0,29 & 29,7 \\
\hline $2 \times 15$ & $-0,20$ & $-8,8$ & $6 \times 8$ & $-0,15$ & $-4,0$ & $11 \times 13$ & 0,01 & 1,5 \\
\hline $3 \times 4$ & 0,47 & 28,9 & $6 \times 9$ & $-0,02$ & 9,7 & $11 \times 14$ & 0,27 & 23,0 \\
\hline $3 \times 5$ & 0,37 & 24,5 & $6 \times 10$ & 0,02 & 4,2 & $11 \times 15$ & $-0,06$ & $-3,0$ \\
\hline $3 \times 6$ & 0,18 & 12,6 & $6 \times 11$ & 0,00 & 3,6 & $12 \times 13$ & 0,45 & 35,6 \\
\hline $3 \times 7$ & 0,09 & 5,6 & $6 \times 12$ & 0,49 & 33,0 & $12 \times 14$ & 0,98 & 88,2 \\
\hline $3 \times 8$ & 0,07 & 3,4 & $6 \times 13$ & 0,03 & 2,7 & $12 \times 15$ & 0,28 & 29,9 \\
\hline $3 \times 9$ & 0,41 & 26,9 & $6 \times 14$ & 0,44 & 26,1 & $13 \times 14$ & 0,50 & 34,7 \\
\hline $3 \times 10$ & 0,49 & 28,7 & $6 \times 15$ & 0,35 & 24,5 & $13 \times 15$ & 0,37 & 21,9 \\
\hline $3 \times 11$ & $-0,07$ & $-3,3$ & $7 \times 8$ & 0,61 & 38,4 & $14 \times 15$ & 0,29 & 25,3 \\
\hline
\end{tabular}

${ }^{(1)}$ Descritos na Tabela 1.

Tabela 5. Estratificação ambiental por meio de análise de fatores, com 21 genótipos de soja avaliados em 15 ambientes nos estados do Paraná e Santa Catarina, em três safras.

\begin{tabular}{|c|c|c|c|c|c|c|c|c|c|c|}
\hline \multirow[t]{2}{*}{$\lambda^{(1)}$} & \multirow[t]{2}{*}{$\%^{(2)}$} & \multirow[t]{2}{*}{ Ambiente } & \multirow[t]{2}{*}{ Ano } & \multicolumn{6}{|c|}{ Carga fatorial após rotação } & \multirow[t]{2}{*}{$\varphi^{(3)}$} \\
\hline & & & & Fator 1 & Fator 2 & Fator 3 & Fator 4 & Fator 5 & Fator 6 & \\
\hline 4,38 & 29,21 & Palotina & $2002 / 2003$ & 0,156 & $-0,035$ & 0,106 & $-0,116$ & 0,176 & 0,856 & 0,814 \\
\hline 3,41 & 51,94 & Brasilândia do Sul & $2002 / 2003$ & 0,283 & 0,083 & $-0,086$ & $-0,127$ & 0,126 & 0,838 & 0,829 \\
\hline 1,73 & 63,46 & Marilândia do Sul & $2002 / 2003$ & 0,571 & 0,479 & $-0,141$ & $-0,041$ & 0,035 & 0,062 & 0,582 \\
\hline 1,26 & 71,88 & Entre Rios & $2002 / 2003$ & 0,893 & 0,052 & $-0,248$ & 0,073 & 0,208 & 0,056 & 0,913 \\
\hline 0,91 & 77,96 & Abelardo Luz & $2002 / 2003$ & 0,627 & 0,021 & $-0,293$ & $-0,128$ & $-0,447$ & 0,037 & 0,698 \\
\hline 0,83 & 83,46 & Cascavel & $2002 / 2003$ & 0,114 & 0,176 & $-0,918$ & 0,006 & $-0,121$ & $-0,009$ & 0,902 \\
\hline 0,72 & 88,28 & Castro & $2002 / 2003$ & 0,212 & 0,049 & 0,235 & $-0,225$ & 0,855 & 0,052 & 0,888 \\
\hline 0,54 & 91,87 & Centenário do Sul & $2002 / 2003$ & 0,005 & $-0,135$ & $-0,073$ & 0,019 & 0,821 & 0,401 & 0,859 \\
\hline 0,47 & 95,01 & Faxinal & $2002 / 2003$ & 0,751 & 0,133 & 0,166 & 0,053 & 0,121 & 0,415 & 0,799 \\
\hline 0,33 & 97,19 & Marilândia do Sul & $2001 / 2002$ & 0,833 & 0,195 & 0,092 & $-0,142$ & 0,019 & 0,256 & 0,827 \\
\hline 0,25 & 98,88 & Castro & $2001 / 2002$ & $-0,067$ & 0,121 & 0,012 & 0,898 & $-0,125$ & $-0,198$ & 0,880 \\
\hline 0,08 & 99,43 & Guarapuava & $2001 / 2002$ & 0,268 & 0,806 & $-0,306$ & 0,278 & $-0,140$ & $-0,119$ & 0,926 \\
\hline 0,06 & 99,85 & Palotina & $2000 / 2001$ & $-0,026$ & 0,833 & 0,155 & $-0,153$ & 0,132 & 0,212 & 0,804 \\
\hline 0,02 & 99,96 & Guarapuava & $2000 / 2001$ & 0,257 & 0,846 & $-0,257$ & 0,246 & $-0,157$ & $-0,084$ & 0,939 \\
\hline 0,01 & 100,00 & Brasilândia do Sul & $2000 / 2001$ & $-0,541$ & 0,484 & $-0,422$ & $-0,321$ & $-0,142$ & $-0,183$ & 0,862 \\
\hline
\end{tabular}

(1) Autovalores. ${ }^{(2)}$ Proporção da variação explicada pelos autovalores. ${ }^{(3)}$ Comunalidades. 
sendo que Brasilândia do Sul, em 2002/2003, apresentou ausência de interação com outros sete ambientes, o que permitiu seu posicionamento no grupo B. Na safra 2002/2003, estas localidades apresentaram alto porcentual de PS $(74,4 \%)$, ao passo que, na safra 2000/2001, a maior porção atuante foi a de natureza complexa (PS\% = 21,9). Este último fato pode ter refletido no agrupamento por análise de fatores, uma vez que o método de Lin apenas considera se há ou não interação GxA, mas não a quantifica. Quanto à análise de fatores, por considerar a similaridade existente entre os ambientes, pode ter sido afetada indiretamente pelo alto percentual de parte complexa, e pela baixa correlação $(r=0,37)$, que ocorreu na safra 2000/2001, entre estas localidades. Desse modo, essas duas localidades poderiam ser reduzidas a somente um local de ensaio, no caso da ocorrência de uma eventual escassez de recursos ou problemas operacionais.

Com exceção de Guarapuava, agrupada nos dois métodos, e com predominância de PS\% na interação GxA, os locais que se repetiram em mais de uma safra (Palotina, Brasilândia do Sul, Marilândia do Sul e Castro), não foram agrupados pela análise de fatores e, pelo método de Cruz \& Castoldi (1991), não atingiram 70\% de PS atuante, com correlação abaixo de 0,80. A distinção no desempenho dos genótipos nessas localidades, em função da variação de ano para ano, mais especificamente na safra 2000/2001, deve-se a problemas técnicos ocorridos na condução dos experimentos nessas localidades.

\section{Conclusões}

1. A técnica de análise de fatores associada ao porcentual de parte simples da interação GxA é mais seletiva no processo de estratificação ambiental do que o método tradicional de Lin.

2. Palotina e Brasilândia do Sul podem ser reduzidos a somente um local de ensaio.

3. Pelos parâmetros obtidos nas análises de regressão linear única e bissegmentada, e pelo elevado potencial produtivo, o genótipo RB 605 pode ser indicado para cultivo em todos os ambientes de estudo.

\section{Referências}

CONAB. Acompanhamento da safra brasileira: grãos: décimo segundo levantamento, setembro de 2007. Brasília: Conab, 2007. 26p.
BANZATO, D.A.; KRONKA, S.N. Experimentação Agrícola. Jaboticabal: Funep, 1989. 247p.

CARNEIRO, P.C.S. Novas metodologias de análise de adaptabilidade e estabilidade de comportamento. 1998. 168p. Tese (Doutorado) - Universidade Federal de Viçosa, Viçosa.

CARVALHO, C.G.P.; ARIAS, C.A.A.; TOLEDO, J.F.F.; ALMEIDA, L.A.; KIIHL, R.A.S.; OLIVEIRA, M.F. Interação genótipo x ambiente no desempenho produtivo da soja no Paraná. Pesquisa Agropecuária Brasileira, v.37, p.989-1000, 2002.

CRUZ, C.D. Genes v.2005.0.0: aplicativo computacional em genética e estatística. Viçosa: Universidade Federal de Viçosa, Departamento de Biologia Geral, 2005. Disponível em: http://www.ufv.br/dbg/genes/ genes.htm. Acesso em: jan. 2007.

CRUZ, C.D.; CARNEIRO, P.C.S. Modelos biométricos aplicados ao melhoramento genético. Viçosa: UFV, 2003. v.2. 585p.

CRUZ, C.D.; CASTOLDI, F. Decomposição da interação genótipos $\mathrm{x}$ ambientes em partes simples e complexa. Revista Ceres, v.38, p.422-430, 1991.

CRUZ, C.D.; REGAZZI, A.J.; CARNEIRO, P.C.S. Modelos biométricos aplicados ao melhoramento genético. Viçosa: UFV, 2004. v.1. 480p.

CRUZ, C.D.; TORRES, R.A.; VENCOVSKY, R. An alternative approach to the stability analysis proposed by Silva and Barreto. Revista Brasileira de Genética, v.12, p.567-580, 1989.

DI MAURO, A.O.; CURCIOLI, V.B.; NÓBREGA, J.C.M.; BANZATO, D.A.; SEDIYAMA, T. Correlação entre medidas paramétricas e não-paramétricas de estabilidade em soja. Pesquisa Agropecuária Brasileira, v.35, p.687-696, 2000.

EBERHART, S.A.; RUSSEL, W.A. Stability parameters for comparing varieties. Crop Science, v.6, p.36-40, 1966.

GARBUGLIO, D.D.; GERAGE, A.C.; ARAÚJO, P.M.; FONSECA JUNIOR, N.S.; SHIOGA, P.S. Análise de fatores e regressão bissegmentada em estudos de estratificação ambiental e adaptabilidade em milho. Pesquisa Agropecuária Brasileira, v.42, p.183-191, 2007.

HAMAWAKI, O.T.; SANTOS, P.G. Adaptabilidade e estabilidade de genótipos de milho avaliadas por meio do modelo de regressão. Ciência Rural, v.33, p.195-199, 2003.

KANG, M.S. Using genotype-by-environment interaction for crop cultivar development. Advances in Agronomy, v.62, p.199-252, 1998.

LIN, C.S. Grouping genotypes by a cluster method directly related to genotype-environment interaction mean square. Theoretical and Applied Genetics, v.62, p.277-280, 1982.

MARIOTTI, J.A.; OYARZABAL, E.S.; OSA, J.M.; BULACIO, A.N.R.; ALMADA, G.H. Análisis de estabilidad y adaptabilidad de genótipos de caña-de-azúcar. I: interacciones dentro de una localidad experimental. Revista Agronômica do Noroeste Argentino, v.13, p.105-127, 1976.

MORAIS, O.P. Adaptabilidade, estabilidade de comportamento e correlações fenotípicas, genotípicas e de ambiente em variedades e linhagens de arroz (Oryza sativa L.). 1980. 70p. Dissertação (Mestrado) - Universidade Federal de Viçosa, Viçosa. 
MURAKAMI, D.M.; CRUZ, C.D. Proposal of methodologies for environment stratification and analysis of genotype adaptability. Crop Breeding and Applied Biotechnology, v.4, p.7-11, 2004.

OLIVEIRA, A.B.; DUARTE, J.B.; PINHEIRO, J.B. Emprego da Análise AMMI na avaliação da estabilidade produtiva em soja. Pesquisa Agropecuária Brasileira, v.38, p.357-364, 2003.

OLIVEIRA, A.M.S.; HAMAWAKI, O.T.; OLIVEIRA NETO, J.O.; PENNA, J.C.V.; JULIATTI, F.C.; SOUZA, S.A. Estabilidade fenotípica de cultivares de soja no Brasil central. Bioscience Journal, v.20, p.9-19, 2004.
PRADO, E.E.; HIROMOTO, D.M.; GODINHO, V.P.C.; UTUMI, M.M.; RAMALHO, A.R. Adaptabilidade e estabilidade de cultivares de soja em cinco épocas de plantio no cerrado de Rondônia. Pesquisa Agropecuária Brasileira, v.36, p.625-635, 2001.

SAS INSTITUTE. SAS/STAT software: changes and enhancements through release 8.02. Cary: SAS, 1999. 3 CD-ROM.

SILVA, W.C.J. e; DUARTE, J.B. Métodos estatísticos para estudo de adaptabilidade e estabilidade fenotípica em soja. Pesquisa Agropecuária Brasileira, v.41, p.23-30, 2006.

Recebido em 27 de julho de 2007 e aprovado em 16 de outubro de 2007 